\title{
Atividade antibacteriana de extrato hidro-alcoólico de folhas de jambolão (Syzygium cumini (L.) Skells)
}

\author{
Antibacterial activity of hydro-alcoholic extract leaves of jambolan (Syzygium cumini (L.) Skells)
}

\author{
Andrea Pinto Loguercio ${ }^{1}$ Alice Battistin ${ }^{2}$ Agueda Castagna de Vargas ${ }^{3}$ \\ Andréia Henzel ${ }^{4}$ Niura Mazzini Witt ${ }^{5}$
}

\section{RESUMO}

A atividade antimicrobiana de plantas medicinais tem sido pesquisada em diversas espécies, tanto no Brasil quanto em outros países. $O$ objetivo deste trabalho foi o de avaliar a existência de efeito antibacteriano de extrato hidro-alcoólico a $10 \%(\mathrm{~m} / \mathrm{v})$ de folhas de jambolão. Utilizaram-se 17 isolados bacterianos, Gram positivos e Gram negativos. A ação antibacteriana foi avaliada através da inoculação de placas de ágar Mueller Hinton, com um inóculo bacteriano de $1 \times 10^{6}$ ufc $\mathrm{mL}^{-1}$, onde se colocaram quatro discos de papel; o primeiro de antimicrobiano comercial e os demais embebidos em $25 \mu \mathrm{L}$ do extrato, de solução salina ou de etanol. As placas foram incubadas a $37^{\circ} \mathrm{C}$ por 24 horas, sendo posteriormente realizada a leitura do diâmetro dos halos de inibição. O extrato inibiu o crescimento de $100 \%$ das bactérias testadas e os isolados Gram positivos apresentaram um halo médio de 19,5mm, enquanto o dos Gram negativos foi de $18,8 \mathrm{~mm}$. Não houve inibição significativa de crescimento nos tratamentos com salina e etanol. Conforme os resultados deste estudo, o extrato testado apresenta atividade antibacteriana frente às amostras testadas, sem diferença de sensibilidade entre microrganismos Gram positivos e Gram negativos.

Palavras-chave: planta medicinal, antimicrobiano, jambolão.

\section{ABSTRACT}

The antimicrobial activity of medicinal plants has been searched in diverse species, as much in Brazil as in other countries. The aim of this study was to evaluate the existence of hydro-alcoholic extract jambolan leaves $10 \%$ $(w / v)$ antibacterial effect. Seventeen Gram positive and Gram negative isolated bacterial were used. The antibacterial action was evaluated through the inoculation of Mueller Hinton agar plates, with a bacterial inoculate of $3 \times 10^{8}$ cell $\mathrm{mL}$, with four paper discs, being the first of commercial antimicrobial and the others embedded with $25 \mu \mathrm{L}$ of the extract, saline or ethanol. The plates were incubated at $37^{\circ} \mathrm{C}$ for 24 hours, and their reading of inhibition hales diameter was done. The extract inhibited the growth of $100 \%$ of the tested bacteria; the Gram positive isolates had presented an average hale of $19.5 \mathrm{~mm}$, while of the Gram negative was of $18.8 \mathrm{~mm}$. There was not significant inhibition of growth in treatments with saline and ethanol. As verified in this study, the tested extract presents antibacterial activity against all the isolates, without sensitivity difference among Gram positive and Gram negative microorganisms.

Key words: medicinal plant, antimicrobial, jambolan

\section{INTRODUÇÃO}

Desde 1977, a Organização Mundial da Saúde (OMS) tem incentivado o estudo de plantas tradicionalmente conhecidas como medicinais, com o objetivo de avaliar cientificamente os benefícios da utilização de medicamentos fitoterápicos e de conhecer, ao mesmo tempo, os riscos de seu uso indevido. Muitos centros de pesquisa, em todo o mundo, vêm desenvolvendo estudos sobre as propriedades

${ }^{1}$ Engenheiro Agrônomo, Doutor, Professor Adjunto, Universidade Estadual do Rio Grande do Sul (UERGS). Av. Júlio de Castilhos, 3947, UERGS Unidade de Caxias do Sul, 95010-005, Caxias do Sul, RS. E-mail: andrea-loguercio@uergs.edu.br. Autor para correspondência.

${ }^{2}$ Biólogo, Doutor, Fundação Estadual de Pesquisa Agropecuária (FEPAGRO), Porto Alegre, RS

${ }^{3}$ Médico Veterinário, Doutor, Professor Adjunto, Departamento de Medicina Veterinária Preventiva (DMVP), Centro de

Ciências Rurais (CCR), Universidade Federal de Santa Maria (UFSM), Santa Maria, RS

${ }^{4}$ Acadêmico, curso de Medicina Veterinária, UFSM.

${ }^{5}$ Médico Veterinário, Fundação de Apoio à Ciência e Tecnologia (FATEC), UFSM. 
farmacológicas das plantas medicinais. No entanto, faltam ainda evidências laboratoriais e clínicas sobre a eficácia e a segurança de seu emprego, tanto em animais como em seres humanos. Os supostos méritos terapêuticos que possuem devem-se, principalmente, a informações empíricas e subjetivas da medicina folclórica (YUNES \& CECHINEL FILHO, 2001).

Apesar das indústrias farmacêuticas produzirem um expressivo número de novos antibióticos nas últimas três décadas, a resistência microbiana a essas drogas também aumentou. Em geral, as bactérias têm a habilidade genética de adquirir e de transmitir resistência às drogas utilizadas como agentes terapêuticos (COHEN, 1992). O problema da resistência microbiana é crescente e a perspectiva futura do uso de drogas antimicrobianas, incerta. Torna-se urgente adotar, portanto, medidas de enfrentar o problema, entre elas a do controle no uso de antibióticos, a do desenvolvimento de pesquisas para uma melhor compreensão dos mecanismos genéticos da resistência microbiana e a da continuação dos estudos acerca de novas drogas, sintéticas e naturais (NASCIMENTO et al., 2000).

$\mathrm{O}$ uso de extratos vegetais e fitoquímicos de conhecida atividade antimicrobiana podem adquirir significado nos tratamentos terapêuticos. Desenvolvem-se inúmeros estudos, em diferentes países, para comprovar-lhes a eficácia (NUNAN et al., 1985; LOCHER et al., 1995; ANNAPURNA et al., 1999; DJIPA et al., 2000; FERESIN et al., 2001; KHAN et al., 2001; RAMESH et al., 2002). Muitas espécies vegetais têm sido usadas, pelas características antimicrobianas, através de compostos sintetizados pelo metabolismo secundário da planta. Estes produtos são reconhecidos por suas substâncias ativas, como é o caso dos compostos fenólicos, que fazem parte dos óleos essenciais e dos taninos (NASCIMENTO et al., 2000).

No Brasil, também se realizam importantes pesquisas sobre a atividade antimicrobiana de vegetais. A ação inibitória de Vatairea macrocarpa sobre Klebsiella sp. e Staphylococcus aureus foi observada (MATOS et al., 1988). Um estudo detalhado dos componentes antimicrobianos avaliou extratos de 120 espécies de plantas de 28 famílias botânicas diferentes. Oitenta e um desses extratos, obtidos de 58 plantas, revelaramse ativos contra $S$. aureus, enquanto cinco extratos, de quatro plantas, inibiram o crescimento de Pseudomonas aeruginosa (SANTOS-FILHO et al., 1990). Outra pesquisa detectou atividade antibacteriana e antifúngica em óleos essenciais obtidos das folhas de Croton triangularis e identificou ação antifúngica nos extratos de Lippia gracilis e de Xylopia sericea (LEMOS et al., 1992). A investigação da atividade antimicrobiana e da citotoxicidade nos extratos de 30 plantas, contra cinco espécies bacterianas e duas fúngicas, foi realizada por NASCIMENTO et al. (1990). Os autores concluíram que o extrato etanólico de $70 \%$ das plantas era citotóxico e que somente uma das espécies, Combretum duarteanum, evidenciou atividade antimicrobiana. A ação antimicrobiana de Mikania triangularis, conhecido como guacho-da-folha-fina, foi testada contra cinco diferentes gêneros bacterianos e três gêneros de fungos, sendo comprovada atividade contra Bacillus cereus, Escherichia coli, $\boldsymbol{P}$. aeruginosa, S. aureus e S. epidermidis (CRUZ et al., 1996). Os efeitos de compostos fitoquímicos avaliados por JANSEN et al. (1987) e IZZO et al. (1995) mostraram a atividade antimicrobiana do ácido anacárdico sobre S. aureus, Brevibacterium ammoniagenis, Streptococcus mutans e Propionibacterium acnes.

O jambolão (Syzygium cumini (L.) Skeels) é uma planta da família Mirtaceae, oriunda da Índia oriental, de acordo com MORTON (1987) e bastante conhecida na medicina popular indiana e paquistanesa por seus efeitos hipoglicemiantes (PRINCE et al., 1998). Tem como sinonímia os nomes de Eugenia jambolana (Lam.), Myrtus cumini L., Syzygium jambolanum (Lam.) DC e Eugenia cumini Druce (MARCHIORI \& SOBRAL, 1997). Vem sendo cultivada no Brasil como planta ornamental e o chá de suas folhas é normalmente utilizado por pacientes diabéticos (SILVA NETO, 1987; TEIXEIRA et al., 1990; SOARES et al., 2000). As folhas são ricas em taninos e saponinas. Tanto a casca como as folhas e as sementes são bastante adstringentes. O suco dos frutos é utilizado como adstringente, diurético, antidiabético e estomáquico. As propriedades adstringentes da casca são utilizadas contra diarréias crônicas, disenteria e menorragia. A decocção da casca é um eficaz enxagüante bucal no tratamento de aftas, estomatites, afecções da garganta e outras doenças das vias orais (KAPOOR, 1990).

O termo "tanino" é um nome genérico descritivo para um grupo de substâncias poliméricas fenólicas capazes de curtir couro ou precipitar gelatina em solução, propriedade conhecida como adstringência. São encontradas na maioria dos órgãos vegetais, como casca, caule, folhas, frutos e raízes. Muitas atividades fisiológicas humanas, como a estimulação das células fagocíticas e a ação tumoral mediada por hospedeiro, além de uma larga faixa de atividades antiinfectivas, têm sido atribuídas aos taninos. Uma de suas ações moleculares é a de formar complexos com proteínas 
através de forças denominadas “não-específicas”, como pontes de hidrogênio e ligações hidrofóbicas, assim como pela formação de ligações covalentes (COWAN, 1999).

O mecanismo de ação antimicrobiana dos taninos explica-se por três hipóteses. A primeira pressupõe os taninos inibindo enzimas bacterianas e fúngicas e/ou se complexando com os substratos dessas enzimas; a segunda inclui a ação dos taninos sobre as membranas celulares dos microrganismos, modificando seu metabolismo, e a terceira fundamentase na complexação dos taninos com íons metálicos, diminuindo a disponibilidade de íons essenciais para o metabolismo microbiano (SCALBERT, 1991).

De acordo com os costumes regionais, dentre os inúmeros usos de espécies de Syzygium destaca-se o de seu efeito anti-hiperglicêmico (TEIXEIRA et al., 2000), antiinflamatório (CHAUDHURI et al., 1990) e antimicrobiano (CHATTOPADHYAY et al., 1998; MUKHERJEE et al., 1998; DJIPA et al., 2000; DORMAN \& DEANS, 2000; SHAFI et al., 2002). A forma de administração dos chás e extratos também é bastante variável, de acordo com os princípios etnobotânicos. Os relatos científicos supracitados consideraram, na quase totalidade, o preparo e a administração do extrato ou chá de acordo com o modo tradicional de cada etnia. Assim, a literatura relata extratos aquosos, hidro-alcoólicos e alcoólicos em diversas proporções, feitos a partir de folhas verdes ou secas, de casca, de frutos, de sementes e, até mesmo, de botões florais. O uso de solventes hidroalcoólicos, obtidos a partir de diferentes proporções de água e etanol, é eficiente para a extração bruta de taninos e saponinas (FALKENBERG et al., 2002). O objetivo deste estudo foi o de avaliar a existência de efeito antibacteriano do extrato hidro-alcoólico a $10 \%$ $(\mathrm{m} / \mathrm{v})$ de folhas de jambolão.

\section{MATERIAL E MÉTODOS}

As folhas foram obtidas a partir de árvores de jambolão (Syzygium cumini (L.) Skeels Myrtaceae), cultivadas no Jardim Botânico da Universidade Federal de Santa Maria (UFSM), coletadas em agosto e setembro de 2001, sempre nas primeiras horas da manhã. Seco o material, uma amostra de cada exsicata foi enviada ao Setor de Botânica Sistemática do Departamento de Biologia da UFSM para identificação botânica e registro do exemplar voucher. A secagem do material vegetal foi inicialmente realizada à temperatura ambiente, para perda inicial da umidade e, complementada em estufa, a $50^{\circ} \mathrm{C}$ até obterse um teor-padrão de umidade de $20 \%$. As folhas foram moídas em moinho de grão e misturou-se o pó resultante com solução hidro-alcoólica (etanol 70\%), na proporção de $10 \%\left(\mathrm{~m} \mathrm{v}^{-1}\right)$. Estocou-se essa solução à temperatura ambiente, protegida da luz, por um período de 25 dias, quando se procedeu à filtragem do material. A partir da solução filtrada, produziu-se o extrato, através de extração a $50^{\circ} \mathrm{C}$ e com auxílio de roto-evaporador, a fim de retirar-se todo o solvente. $\mathrm{O}$ evaporado restante recebeu o nome de "extrato hidroalcoólico de jambolão a 10\%" e foi testado.

Selecionaram-se 17 isolados bacterianos, Gram positivos e Gram negativos, de importância patogênica para animais e humanos. Tais isolados integram a bacterioteca do Laboratório de Bacteriologia do Departamento de Medicina Veterinária Preventiva (DMVP) da UFSM, onde se mantêm liofilizados e congelados a $-20^{\circ} \mathrm{C}$. As bactérias foram cultivadas em ágar BHI (Brain Heart Infusion Agar), a $37^{\circ} \mathrm{C}$, durante um período de 24 a 48 horas, dependendo do gênero bacteriano . Os cultivos foram suspensos em solução salina estéril até ajuste da turvação à escala 1 de McFarland (3,0 x $10^{8}$ unidades formadoras de colônias/ $\mathrm{mL}$ ). $\mathrm{O}$ teste de sensibilidade a antimicrobianos foi realizado de acordo com o método de Kirby-Bauer modificado (CARTER \&CHENGAPPA, 1991). Em resumo, o inóculo bacteriano foi semeado em ágar Mueller Hinton e colocando quatro discos de papel estéril, com os respectivos tratamentos; tratamento 1 - disco saturado com $25 \mu \mathrm{L}$ de extrato (28,25mg); tratamento 2 - disco saturado com $25 \mu \mathrm{L}$ de solução salina estéril; tratamento 3 - disco saturado com $25 \mu \mathrm{L}$ de etanol $96^{\circ} \mathrm{GL}$, e tratamento 4 - disco de antimicrobiano comercial variável de acordo com a espécie. Após 24 horas de cultivo a $37^{\circ} \mathrm{C}$, foi feita a leitura dos halos de inibição de crescimento. A concentração de extrato utilizado correspondeu à Concentração Inibitória Mínima (CIM) desse extrato, previamente determinada em outro experimento. Foram utilizadas três repetições por tratamento.

A análise estatística dos dados foi feita com auxílio do software SAS for Windows (versão 6.1) utilizando-se o tese de Duncan a $5 \%$ de probabilidade de erro.

\section{RESULTADOS E DISCUSSÃO}

Os antimicrobianos testados foram classificados em dois grupos principais, um para as bactérias Gram positivas (Grupo 1) e outro para as Gram negativas (Grupo 2). O Grupo 1 consistiu dos seguintes antimicrobianos: Rifampicina (RIF - 5 $\mu \mathrm{g}$ ),

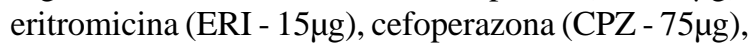

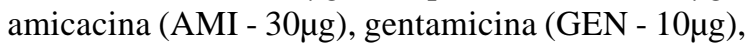




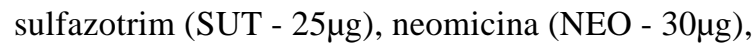

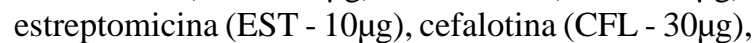

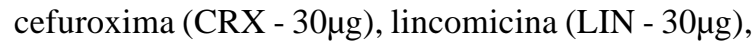
oxacilina (OXA - 1 $\mu \mathrm{g}$ ); no Grupo 2, utilizaram-se os

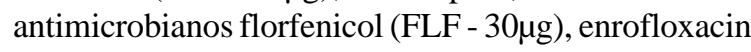

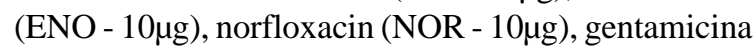

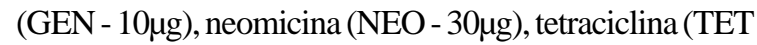

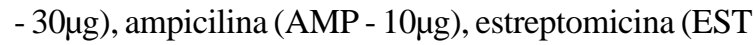

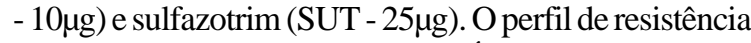
antimicrobiana, determinado pelo Índice de Resistência Antimicrobiana de KRUMPERMAN (1983) é apresentado na tabela 1 .

Na tabela 2, pode-se observar o diâmetro dos halos de inibição resultantes dos quatro tratamentos avaliados. Os achados deste trabalho concordam com os de KHAN et al. (2001), que avaliaram extratos de folhas de Symplocos cochinchinensis, e com os de SRINIVASAN et al. (2001), que estudaram a atividade antimicrobiana de plantas utilizadas na medicina tradicional indiana (Tabela 3). Os autores dos dois estudos obtiveram valores bastante semelhantes ao deste trabalho, incluindo a evidência de valores superiores, ou seja, de maior atividade contra as bactérias Gram positivas.

Pesquisando a atividade antibacteriana de óleos essenciais extraídos de folhas de S. cumini e de outras espécies do gênero, SHAFI et al. (2002) também encontraram valores próximos aos apresentados neste trabalho, no que se refere ao diâmetro dos halos de inibição no teste de difusão em ágar. Os autores trabalharam com $S$. aureus, E. coli, $P$. aeruginosa e Salmonella Typhimurum, ou seja, com cinco das espécies bacterianas aqui pesquisadas, corroborando a hipótese de efetiva atividade antibacteriana do extrato hidro-etanólico de folhas de S. cumini.

ANNAPURNA et al. (1999) relatam atividade antimicrobiana de diferentes extratos, inclusive aquoso, de folhas de Saraca asoca. No entanto, tais extratos apresentaram um diâmetro de inibição superior para bactérias Gram negativas. Uma maior atividade contra esse grupo de bactérias também foi observada por NUNAN et al. (1985), com extrato de folhas de Aristolochia gigantea, e por LOCHER et al. (1995) em diversas espécies medicinais havaianas.

As diferenças de atividade contra esses dois grupos bacterianos parecem derivar da constituição da parede celular bacteriana e dos constituintes do extrato vegetal, principalmente do grupo dos taninos. Conforme os dados deste trabalho e de outros autores (KHAN et al., 2001; SRINAVASAN et al., 2001; CIMANGA et al., 2002), existe uma relação entre o teor de taninos e a atividade contra bactérias Gram positivas, que têm estrutura celular mais rígida, parede celular quimicamente menos complexa e menor teor de lipídico do que as Gram negativas.

Tabela 1 - Perfil de sensibilidade a antimicrobianos das amostras testadas, através do ì́dice de resistência antimicrobiana (IRMA) de KRUPERMAN (1983).

\begin{tabular}{|c|c|c|}
\hline Isolado bacteriano & Sensibilidade aos antimicrobianos testados & IRMA \\
\hline Staphylococcus sp. 147/02 & CFL*, AMI, RIF, CPZ, CRX, OXA, ERI, LIN, GEN, NEO & 0,412 \\
\hline Staphylococcus sp. 558/96 & RIF & 0,941 \\
\hline S. aureus $147 / 02$ & CRX,RIF,CFL,CPZ,SUT & 0,706 \\
\hline S. aureus $144 / 98$ & CRX, CFL, RIF, AMI, LIN, CPZ, NEO, GEN, EST & 0,471 \\
\hline S. intermedius $115 / 92$ & CRX, CFL, RIF, AMI, LIN, ERI, CPZ, NEO, SUT, GEN, OXA, EST & 0,294 \\
\hline S. aureus ATCC 25923 & CPZ, GEN, RIF, LIN, EST, SUT & 0,647 \\
\hline Bacillus cereus $179 / 94$ & AMI, RIF, EST, ERI, GEN & 0,706 \\
\hline Corynebacterium sp. 083/99 & NEO, ERI, GEN, EST, AMI, RIF & 0,647 \\
\hline Rhodococcus equi $488 / 01$ & RIF, CPZ, NEO, GEN, CRX, ERI, EST, AMI & 0,529 \\
\hline Streptococcus canis $154 / 90$ & CPZ, CRX, OXA, LIN, ERI, RIF, CFL, SUT & 0,529 \\
\hline Escherichia coli $120 / 93$ & TET, FLF, ENO, NOR & 0,765 \\
\hline E. coli $158 / 93$ & TET, ENO, GEN, NOR, AMP, FLF, SUT, EST & 0,529 \\
\hline E. coli ATCC 25922 & GEN, EST, AMP, SUT, TET, FLF, ENO & 0,588 \\
\hline Salmonella Typhi. ATCC 6539 & TET, NEO, SUT, EST, FLF, AMP, NOR, GEN, ENO & 0,471 \\
\hline S. Cholerasuis ATCC 10708 & AMP, NOR, FLF, GEN, SUT, EST, ENO, TET & 0,529 \\
\hline Pseudomonas aeruginosa ATCC 27853 & NOR, ENO, GEN, EST & 0,765 \\
\hline Proteus sp. 447/01 & NOR, ENO, GEN, FLF & 0,765 \\
\hline
\end{tabular}

*Legenda: RIF -Rifampicina, AMI - Amicacina, AMP - Ampicilina, CFL - Cefalotina, CPZ - Cefoperazona, CRX - Cefuroxima, ENO Enrofloxacin, ERI - Eritromicina, EST - Estreptomicina, EST - Estreptomicina, FLF - Florfenicol, GEN - Gentamicina, LIN - Lincomicina, NEO - Neomicina, NOR - Norfloxacin, OXA - Oxacilina, SUT - Sulfazotrim, SUT - Sulfazotrim, TET - Tetraciclina. 
Tabela 2 - Diâmetros médios do halo de inibição (em mm) avaliados pelo método de difusão em ágar (Kirby- Bauer)

\begin{tabular}{|c|c|c|c|c|}
\hline Isolado bacteriano & Extrato & Etanol & Sol. salina & Antimicrobiano \\
\hline Staphylococcus sp. 147/02 & $22 a^{*}$ & $5,67 \mathrm{~b}$ & $1,0 \mathrm{c}$ & $4,33 b$ \\
\hline Staphylococcus sp. 558/96 & $20 \mathrm{a}$ & $5 b$ & $6,67 b$ & $8 \mathrm{~b}$ \\
\hline S. aureus $147 / 02$ & $12 \mathrm{a}$ & $6 \mathrm{bc}$ & $2,67 \mathrm{c}$ & $10,67 \mathrm{ab}$ \\
\hline S. aureus $144 / 98$ & $16,33 b$ & $1,67 \mathrm{c}$ & $4 \mathrm{c}$ & $24 \mathrm{a}$ \\
\hline S. intermedius $115 / 92$ & $24 b$ & $5 c$ & $6,33 c$ & $29,33 \mathrm{a}$ \\
\hline S. aureus ATCC 25923 & $26,67 b$ & $2 c$ & $0,67 \mathrm{c}$ & $38,33 \mathrm{a}$ \\
\hline Bacillus cereus $179 / 94$ & $14,67 \mathrm{~b}$ & $4,33 \mathrm{c}$ & $4 \mathrm{c}$ & $22 \mathrm{a}$ \\
\hline Corynebacterium sp. 083/99 & $25,67 b$ & $7,33 \mathrm{c}$ & $7,67 \mathrm{c}$ & $31,67 \mathrm{a}$ \\
\hline Rhodococcus equi 488/01 & $19,67 \mathrm{a}$ & $5 b$ & $5,33 b$ & $22 \mathrm{a}$ \\
\hline Streptococcus canis $154 / 90$ & $15 b$ & $4 \mathrm{c}$ & $3,33 \mathrm{c}$ & $29,67 \mathrm{a}$ \\
\hline Escherichia coli $120 / 93$ & $17 \mathrm{a}$ & $4,33 b c$ & $2,67 \mathrm{c}$ & $8,67 b$ \\
\hline E. coli $158 / 93$ & $17,33 \mathrm{a}$ & $2,33 b$ & $2 b$ & $21,33 \mathrm{a}$ \\
\hline E. coli ATCC 25922 & $23,33 \mathrm{a}$ & $2 \mathrm{c}$ & $0,67 \mathrm{c}$ & $10,67 b$ \\
\hline Salmonella Typhi. ATCC 6539 & $22,67 b$ & $1,33 \mathrm{c}$ & $1,67 \mathrm{c}$ & $31,33 \mathrm{a}$ \\
\hline S. Cholerasuis ATCC 10708 & $24,33 \mathrm{a}$ & $1,33 \mathrm{c}$ & $2,67 \mathrm{c}$ & $18,33 \mathrm{~b}$ \\
\hline Pseudomonas aeruginosa ATCC 27853 & $21 b$ & $1,33 \mathrm{c}$ & $2 c$ & $30 \mathrm{a}$ \\
\hline Proteus sp. $447 / 01$ & $12,67 \mathrm{a}$ & $1 \mathrm{c}$ & $0,67 \mathrm{c}$ & $9,33 b$ \\
\hline
\end{tabular}

* Médias seguidas de letras desiguais diferem entre si pelo tese de Duncan em nível de 5\% de probabilidade de erro.

Tabela 3 - Antimicrobianos comerciais utilizados como controle positivo no teste de difusão.

\begin{tabular}{|c|c|c|}
\hline Isolado bacteriano & Antimicrobiano & Concentração \\
\hline 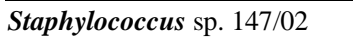 & Gentamicina & $10 \mu \mathrm{g}$ \\
\hline Staphylococcus sp. 558/96 & Gentamicina & $10 \mu \mathrm{g}$ \\
\hline S. aureus $147 / 02$ & Rifampicina & $05 \mu \mathrm{g}$ \\
\hline S. aureus $144 / 98$ & Gentamicina & $10 \mu \mathrm{g}$ \\
\hline S. intermedius $115 / 92$ & Gentamicina & $10 \mu \mathrm{g}$ \\
\hline S. aureus ATCC 25923 & Gentamicina & $10 \mu \mathrm{g}$ \\
\hline Bacillus cereus $179 / 94$ & Gentamicina & $10 \mu \mathrm{g}$ \\
\hline Corynebacterium sp. 083/99 & Gentamicina & $10 \mu \mathrm{g}$ \\
\hline Rhodococcus equi 488/01 & Gentamicina & $10 \mu \mathrm{g}$ \\
\hline Streptococcus canis $154 / 90$ & Rifampicina & $05 \mu \mathrm{g}$ \\
\hline Escherichia coli $120 / 93$ & Tetraciclina & $30 \mu \mathrm{g}$ \\
\hline E. coli $158 / 93$ & Tetraciclina & $30 \mu \mathrm{g}$ \\
\hline E. coli ATCC 25922 & Tetraciclina & $30 \mu \mathrm{g}$ \\
\hline SalmonellaTyphi ATCC 6539 & Tetraciclina & $30 \mu \mathrm{g}$ \\
\hline S. Cholerasuis ATCC 10708 & Tetraciclina & $30 \mu \mathrm{g}$ \\
\hline $\begin{array}{l}\text { Pseudomonas aeruginosa } \\
\text { ATCC } 27853\end{array}$ & Gentamicina & $10 \mu \mathrm{g}$ \\
\hline Proteus sp. 447/01 & Gentamicina & $10 \mu \mathrm{g}$ \\
\hline
\end{tabular}

\section{CONCLUSÕES}

Conforme verificado neste estudo, o extrato hidro-alcoólico a $10 \%(\mathrm{~m} / \mathrm{v})$ de folhas de jambolão (S. cumini (L.) Skeels) apresenta atividade antibacteriana frente a 17 isolados bacterianos testados, não sendo observada diferença de sensibilidade entre microorganismos Gram positivos e Gram negativos.

\section{REFERÊNCIAS BIBLIOGRÁFICAS}

ANNAPURNA, J. et al. Antimicrobial activity of Saraca asoca leaves. Fitoterapia, Milão, v.70, n.1, p.80-82, 1999.

CARTER, G.R.; CHENGAPPA, M.M. Essentials of veterinary bacteriology and mycology. 4.ed. Londres: Lea \& Febiger, 1991. 284p.

CHATTOPADHYAY, D. et al. Antibacterial activity of Syzygium species. Fitoterapia, Milão, v.69, n.4, p.365-367, 1998.

CHAUDHURI, A.K.N. et al. Anti-inflammatory and related actions of Syzygium cuminii seed extract. Phytotherapy Research, West Sussex, v.4, n.1, p.5-10, 1990

CIMANGA, K. et al. Correlation between chemical composition and antibacterial activity of essential oils of some aromatic medicinal plants growing in the Democratic Republic of Congo. Journal of Ethnopharmacology, Limerick, v.79, n.2, p.213-220, 2002.

COHEN, M.L. Epidemiology of drug resistance: implications for a post-antimicrobial era. Science, Washington, v.257, n.11, p.1050-1055, 1992.

COWAN, M.M. Plant products as antimicrobial agents. Clinical Microbiology Reviews, Washington, v.12, n.4, p.564-582, 1999.

CRUZ, F.G. et al. Antibiotic activity of diterpenes from Mikania triangularis. Fitoterapia, Milão, v.67, n.1, p.189190, 1996.

DJIPA, C.D. et al. Antimicrobial activity of bark extracts of Syzygium jambos (L.) Alston (Myrtaceae). Journal of Ethnopharmacology, Limerick, v.71, n.1-2, p.307-313, 2000 . 
DORMAN, H.J.D.; DEANS, S.G. Antimicrobial agents from plants: antibacterial activity of plant volatile oils. Journal of Applied Microbiology, Oxford, v.88, n.2, p.308-316, 2000.

FALKENBERG, M.B. et al. Introdução à análise fitoquímica. In: SIMÕES, C.M.O. (org.). Farmacognosia- da planta ao medicamento. 4.ed. Porto Alegre/ Florianópolis : UFRGS/ UFSC, 2002. Cap.4, p.63-72.

FERESIN, G.E. et al. Antimicrobial activity of plants used in traditional medicine of San Juan province, Argentine. Journal of Ethnopharmacology, Limerick, v.78, n.1, p.103107, 2001.

IZZO, A.A. et al. Biological screening of Italian medicinal plants for antibacterial activity. Phytotherapy Research, West Sussex, v.9, n.4, p.281-286, 1995.

JANSEN, A.M. et al. Antimicrobial activity of essencial oils: a 1976-1986 literature review. Aspects of test methods. Planta Medica, Stuttgart, v.40, n.4, p.395-398, 1987.

KAPOOR, L.D. CRC Handbook of ayuverdic medicinal plants. Boca Raton : CRC, 1990. 416p.

KHAN, M.R. et al. Antimicrobial activity of Symplocos cochinchinensis. Fitoterapia, Milão, v.72, n.7, p.825-828, 2001.

KRUMPERMAN, P.H. Multiple antibiotic resistance indexing of Escherichia coli to identify high-risk sources of fecal contamination of foods. Applied and Environmental Microbiology, Washington, v.46, n.1, p.165-170, 1983.

LEMOS, T.L.G. et al. Chemical composition and antimicrobial activity of essential oils from Brazilian plants. Fitoterapia, Milão, v.63, n.2, p.266-268, 1992.

LOCHER, C.P. et al. Antimicrobial activity and anticomplement activity of extracts obtained from selected Hawaiian medicinal plants. Journal of Ethnopharmacology, Limerick, v.49, n.1, p.23-32, 1995.

MARCHIORI, J.N.; SOBRAL, M. Dendrologia das angiospermas: myrtales. Santa Maria : UFSM, 1997. 304p.

MATOS, F.J.A. et al. Chemical constituents and antimicrobial activity of Vatairea macrocarpa Ducke. Acta Amazonica, Manaus, v.18, n.3, p.351-352, 1988.

MORTON, J. Jambolan. In: MORTON, J. Fruits of warm climates. Miami : Creative Resource Systems, 1987. p.375-378.

MUKHERJEE, P.K. et al. Screening of anti-diarrhoeal profile of some plant extracts of a specific region of West Bengal, India. Journal of Ethnopharmacology, Limerick, v.60, n.1, p.85-89, 1998

NASCIMENTO, G.G.F. et al. Antibacterial activity of plant extracts and phytochemicals on antibiotic-resistant bacteria.
Brazilian Journal of Microbiology, São Paulo, v.31, n.2, p.247-256, 2000.

NASCIMENTO, S.C. et al. Antimicrobial and cytotoxic activities in plants from Pernambuco, Brazil. Fitoterapia, Milão, v.61, n.3, p.353-355, 1990.

NUNAN, E.A. et al. Estudo da atividade antimicrobiana de extrato de folha de Aristolochia gigantea Mart. E Zucc. Revista de Farmácia e Bioquímica, Belo Horizonte, v.6, n.1, p.33-40, 1985.

PRINCE, P. et al. Hypoglycaemic activity of Syzygium cumini seeds: effect on lipid peroxidation in alloxan diabetic rats. Journal of Ethnopharmacology, Limerick, v.61, n.1, p.17, 1998.

RAMESH, N. et al. Phytochemical and antimicrobial studies of Begonia malabarica. Journal of Ethnopharmacology, Limerick, v.79, n.1, p.129-132, 2002.

SANTOS-FILHO, D. et al. Atividade antibacteriana de extratos vegetais. Revista de Ciências Farmacêuticas, São Paulo, v.12, n.1, p.39-46, 1990.

SCALBERT, A. Antimicrobial properties of tannins. Phytochemistry, Chichester, v.30, n.12, p.3875-3883, 1991.

SHAFI, P.M. et al. Antibacterial activity of Syzygium cumini and Syzygium travancorium leaf essential oils. Fitoterapia, Milão, v.73, n.4, p.414-416, 2002.

SILVA NETO, C.R. et al. Efeitos antagônicos de plantas medicinais na diurese de ratos. Pesquisa Homeopática, São Paulo, v.4, n.1, p.17-21, 1987.

SOARES, J.C.M. et al. Níveis glicêmicos de colesterol em ratos com Diabetes Mellitus aloxano induzido, tratados com infusão de Bauhinia candicans ou Syzygium jambolanum. Ciência Rural, Santa Maria, v.30, n.1, p.113-118, 2000.

SRINIVASAN, D. et al. Antimicrobial activity of certain Indian medicinal plants used in folkloric medicine. Journal of Ethnopharmacology, Limerick, v.74, n.2, p.217-220, 2001 .

TEIXEIRA, C.C. et al. Effect of tea prepared from leaves of Syzygium jambos on glucose tolerance in non-diabetes subjects. Diabetes Care, Alexandria, v.13, n.8, p.907-908, 1990.

TEIXEIRA, C.C. et al. Absence of antihyperglycemic effect of jambolan in experimental and clinical models. Journal of Ethnopharmacology, Limerick, v.71, n.1-2, p.343-347, 2000.

YUNES, R.A.; CECHINEL FILHO, V. Breve análise histórica de plantas medicinais: sua importância na atual concepção de fármaco segundo os paradigmas ocidental e oriental. In: YUNES, R.A.; CALIXTO, J.B. (eds.). Plantas medicinais sob a óptica da química medicinal moderna. Chapecó: Argos, 2001. p.17-46. 